\title{
What can other countries learn from South Korea's COVID-19 responses?
}

\author{
*Prakash Shahi', Pasang Devi Tamang 1,2, Yagya Bahadur Rokaya³
}

\section{Author Info:}

${ }^{1}$ Manavta, Research and Development Consultant, Nepal

${ }^{2}$ University of Huddersfield, Postgraduate Researcher, Huddersfield, UK

${ }^{3}$ Karnali Academy of Health Science, Lecturer, Jumla, Nepal

*Corresponding Author: Mr. Prakash Shahi;

Email/ Contact:

prakash@manavtaproject.com $+447934531640$

\section{ABSTRACT}

The COVID-19 pandemic is rapidly growing and has been a major challenge for the health system globally. As of 27 April 2020, 213 countries around the world are struggling to combat the spreading the virus with $28,58,635$ confirmed cases and 1,96,295 confirmed deaths. The first case in South Korea was identified on 20 Jan 2020 but the number of confirmed cases started to increase rapidly on end of February 2020 with total of 7,513 cases reported as of 10 March 2020, second country to have experience outbreak.

South Korea's effort to control the virus combined many approaches, such as organized and no negligence in response, extensive screening, provision of improved information and the use of technology. This experience could provide some valuable lessons for countries on response to control the spread of pandemic disease like COVID-19 or any other outbreak situation in coming days or for those who are yet to face the COVID-19 outbreak so that they can control the disease spread in early phase.

In this article, we explore about the strategies used by South Korea to stifle the pandemic who were hit so bad by COVID-19 from the very early stage and discuss how countries can response the process to control the disease like COVID-19 or any other outbreak situations in future.

Keywords: COVID-19, Pandemic, Response, South Korea

Article Info
Received: 8 April 2020; Accepted: 11 May 2020; Published Online: 12 May 2020
Shahi P, Tamang PD, Rokaya YB. What can other countries learn from South Korea's COVID-19
responses? Europasian J Med Sci.2020;2(1):90-93. https://doi.org/10.46405/ejms.V2i1.51
Disclaimer




\section{INTRODUCTION}

Corona virus pandemic is an ongoing viral disease that has been infecting human population globally. The disease caused by the novel Coronavirus has been named 'COVID-19' (where "CO" stands for corona, "VI" for virus, " $\mathrm{D}$ " for disease and "19" indicates the year in which it occurred). This was announced on 11 February 2020 by the DirectorGeneral of the WHO, Dr. Tedros Adhanom Ghebreyesus. ${ }^{1}$ Coronavirus was identified for the first time in Wuhan, china in December 2019. The outbreak was declared public health emergency of international concern on 30 Jan 2020 and recognized as pandemic on 11 March 2020 by World Health Organization (WHO). ${ }^{2}$

On March 10, 2020 South Korea had 7,513 cases the only country other than China with more cases i.e. second country to have experience outbreak. ${ }^{3}$ However, the COVID-19 pandemic is rapidly growing around the world and is considered as today's public health emergency.2,4 To date, 213 countries around the world are struggling to combat the rapidly spreading COVID-19 pandemic with 28,58,635 confirmed cases and 1,96,295 confirmed deaths as of April 27, 2020, 15:50 GMT. ${ }^{5}$

\section{Organized and No Negligence in response}

In Korea the first case was reported on 20 January 2020 with the first death was recorded on 20 February 2020.5 Then on 23 February 2020, Korea raised the national infectious disease crisis level to serious where most of the country like Italy, UK and USA lacks to recognize on time even though several scientists had been warning of potential devastation. ${ }^{6}$

At Central level, Government implemented Central Disease and Safety Countermeasures Headquarters (CDSCHQ) lead by Prime Minister or Minister of Public Administration and Security under two government-wide response to COVID-19 i.e. Central disaster management headquarters (Ministry of health and welfare) and government-wide support center, ministry of public administration and security. ${ }^{7}$ This ability to listen to experts highlights in the process to stop spreading the disease and save the lives.

Korea Central disease control headquarters (KCDC) keeps govern for disease control and prevention of the response while first deputy director of $\mathrm{CDSCHQ}$, Ministry of health and welfare assists disease control efforts and second deputy director, Minister of public administration and security is to provide the necessary assistance in matter including coordination between the central government and local municipal governments.

At local level, executed local disaster and safety countermeasures headquarters directed by the head of local government and established hospital sites dedicated to infectious disease and procure sickbeds. Central government helped in areas where local governments faced shortages. ${ }^{7}$

\section{Robust Immigration practice}

In the early stage, South Korea banned on foreigners arriving from Hubei province, strengthened visa screening and tightened quarantine inspections of entrants from china (including Hong Kong, Macau) Italy and Iran. And since March 19, applying special immigration procedures to all passengers entering to Korea i.e. subjected to temperature checks and required to submit a health declaration form and travel record declaration. Entrants must provide their contact information and address within Korea and install the mobile self-diagnosis application and all incoming passengers whether they are showing symptom or not must check and enter their symptoms daily for 14 days on the application for the monitoring purpose. And all the incoming passengers list was provided to each local government to strengthen the inspection network. Beginning from 01 April 2020, the Korean government implemented stronger quarantine inspection measures for everyone coming from 
abroad. Passengers entering the country from abroad who displays sign of fevers or respiratory symptoms during quarantine inspection would require getting diagnosed and tested regardless of whether they are Korean or foreign nationals.

Korean national and foreigners of long-term stay who are asymptomatic would be self-quarantined (14 days) and foreigners of short-term stay who are asymptomatic would be quarantined in separate facilities (14 days). If symptoms developed, required to get diagnosed and tested.

\section{Testing and Extreme Control}

Early detection and testing to all suspected cases of COVID-19 wherever possible are some of the key measures to slowing or stopping the virus from spreading. ${ }^{8}$ As of 16 March 2020, 635 clinics and screening centers are in operations of which 602 centers are equipped to collect samples onsite. Screening model expanded to drive-through testing facilities around the country and a total of 118 institutions had testing kits and equipment to conduct the test. ${ }^{7}$

South Korea started testing widely and tested hundreds of thousands of people for infections and tracking potential carriers using technologies like cell phone and satellite. ${ }^{9}$ South Korea identified their first cases of the COVID-19 in the late January. Since then (as of April 11, 2020) South Korea reported 211 death out of 10,480 confirmed cases after testing 5,10,479 people. $^{7}$ They tested on an average of 12,000 to maximum of 20,000 test a day. ${ }^{9}$

Hundreds of quarantine officers are assigned and given maximum power and authority who focus on detail to track potential patients. Their main goal is to trace all the contacts people may have had with people who have tested positive for COVID-19. In 2015, South Korea confronted sudden and unexpected outbreak of Middle East Respiratory Syndrome (MERS) which was the largest MERS outbreak outside of Middle East, 186 cases caused by coronavirus. ${ }^{10}$ When COVID-19 hit South Korea, the response they had for MERS allowed the country to understand that the testing should be central part of any response of viral epidemic. Hence, testing became the heart of country's coronavirus strategy which set the Korea apart from other nations. ${ }^{11}$

\section{Epidemiologic Survey and Isolation}

One of the many efforts to prevent COVID-19 spread by Korean government was prompt conduction of epidemiological investigation to track infection sources and screen contact; and Isolation of people who have come in contact with patient which are tested positive for COVID-19.

Preliminary investigations of individual cases are being conducted by local governments. The central immediate response teams are providing support to prevent further spread for the outbreaks within healthcare institution and group facilities. When the COVID-19 confirmed case is identified, persons who have had contact with the patient shall be self-quarantined. Contact identified through epidemiological investigation are all put under selfisolation and thoroughly managed by one-on-one basis by the ministry of the interior and safety and local government. Those put under self-isolation are banned from leaving the nation regardless of whether they develop symptoms or not.

\section{Communication Strategies}

Government communication strategies are vital to keep the public informed with actionable information for self-protection, including identification of symptoms and clear guidance for treatment seeking. ${ }^{12,13}$ Korean government has provided continuous and clear communication to the public. They provided daily updates on the daily and cumulative number of covid-19 cases and people released from quarantine, daily deaths, current status of responses and plans to be implemented, guideline and procedures to follow. 
Beside these, the Government uses location data to customize mass messages sent to cellphones, informing every resident when and where a nearby case is confirmed.

It seems like obvious measure, but proper implementation decides their effectiveness. Like other countries South Korea executes detail explanation and general advice about COVID-19 daily through television, newspaper and internet ads, reminding people to avoid crowded places and use appropriate preventative hygiene. ${ }^{14}$ It was one of the effective steps towards controlling the spread of COVID-19.

\section{KEY MESSAGES}

Various studies and current scenario around the world explain that despite the global escalation of infection, South Korea is winning the fight against the COVID-19. The learning from response to MERS epidemic in 2015 was useful in tackling COVID-19. South Korea has been effective in controlling the country's cases and death rate not through travel bans but through organized and no negligence in response, approach of dealing with crisis, testing and extreme control, epidemiologic survey \& isolation and enhanced communication strategies. These are the lessons that the global community could learn on response to control the spread of disease in early phase in case of any outbreak.

\section{REFERENCES}

1. Ministero della Salute. Novel coronavirus. 2020 Accessed April 10, 2020. [Link]

2. Shahi P. COVID-19 related myths and strategies to combat it. Global Public Health Update. 2020. Accessed 21 April 2020. [Link]

3. WHO. Global: Republic of Korea. Confirmed cases over time. World Health Organization. 2020. Accessed April 11, 2020. [Link]

4. ECDC. COVID-19. European centre for disease prevention and control. 2020. Accessed 17 April 2020. [Link]

5. WHO. Coronavirus disease (COVID-19) outbreak situation. World Health Organization. 2020. Accessed April 27, 2020. [Link]

6. Pisano GP, Sadun R, Zanini M. Lesson from Italy's response to coronavirus. Harvard Business Review. 2020. Accessed April 12, 2020. [Link].

7. MOHW. Coronavirus Disease-19, Republic of Korea. Ministry of Health and Welfare. 2020. Accessed April 08, 2020. [Link]

8. World Health Organization. Coronavirus disease 2019 (COVID-19): situation report, 72. Google Scholar

9. Parodi E, Jewkes S, Cha S, Park JM. Italy and South Korea were hit by coronavirus outbreaks at the same time-but have responded differently. World Economic Forum. 2020. Accessed April 11, 2020. [Link]

10. Sabir JS, Lam TT, Ahmed MM, Li L, Shen Y, Abo-Aba SE, Qureshi MI, Abu-Zeid M, Zhang Y, Khiyami MA, Alharbi NS. Co-circulation of three camel coronavirus species and recombination of MERS-CoVs in Saudi Arabia. Science. 2016 Jan 1;351(6268):81-4. https:// doi.org/10.1126/science.aac8608 [Google Scholar]

11. Fleming S. South Korea's Foreign Minister explains how the country contained COVID-19. World Economic Forum. 2020. Accessed April 11, 2020. [Link]

12. Anderson RM, Heesterbeek $H$, Klinkenberg $D$, Hollingsworth TD. How will country-based mitigation measures influence the course of the COVID-19 epidemic?. The Lancet. 2020 Mar 21;395(10228):9314.https://doi.org/10.1016/S0140-6736(20)30567-5 [Google Scholar]

13. Heymann DL, Shindo N. COVID-19: what is next for public health?. The Lancet. 2020 Feb 22;395(10224):542-5.https://doi.org/10.1016/ S0140-6736(20)30374-3 [Google Scholar]

14. Fendos J. Lessons from south Korea's COVID-19 outbreak: the good, bad and ugly. THE DIPLOMAT. 2020. Accessed April 12, 2020. [Link] 